\title{
Preparing a First Change Laboratory Session Linked to the Issue of Homework and Addressing Methodological Challenges
}

\author{
Rollande Deslandes, Ph.D. (corresponding author) \\ Emeritus Professor, Université du Québec à Trois-Rivières \\ E-mail: rollande.deslandes@uqtr.ca \\ Sylvie Barma, Ph.D. \\ Full Professor, Université Laval, Québec \\ E-mail: sylvie.barma@fse.ulaval.ca
}

Received: May 9, 2018 Accepted: June 9, 2018 Published: August 12018

doi:10.5296/jse.v8i3.13173 URL: https://doi.org/10.5296/jse.v8i3.13173

\begin{abstract}
The issue of homework has been generating debates not only in schools but also in scientific circles and the media. In response to the challenging questions regarding that issue, the Conseil supérieur de l'Éducation (2010) recommended a collective consideration of homework at the local level. In this study, we focus on the methodological challenges of the preparation, implementation and analysis of a first session of a Change Laboratory (CL) undertaken in a low SES elementary school. Building on the principle of double-stimulation and focusing on the expansive learning actions taken by 11 teachers, we identified the transformative actions expressed in their discourse. Findings revealed a predominance of expressions related to explicating and criticising. It was possible to make sense of the participants' statements to prepare the next steps of the intervention.
\end{abstract}

Keywords: Homework, double stimulation, Change Laboratory method, expansive learning actions, methodological challenges 


\section{Introduction}

The current paper focuses on the first steps of the preparation of a Change Laboratory to address the ongoing issue of homework in a low SES elementary school. The goal of the intervention was to enhance the collaboration between teachers and parents for the benefit of pupils' achievement and educational success. Deslandes and Barma(2016) suggested to apply the Change Laboratory method based on Cultural-Historical Activity Theory (CHAT) to give teachers and parents a better voice so they become active participants to bring about changes in the way teachers and parents communicate and collaborate. The Change Laboratory (CL), an interventionist research approach rooted in CHAT, aims at bringing to light the origins and systemic causes of a problem by raising questions about it, reformulating it, and envisioning a new form of activity (Engeström \& Sannino, 2010). Indeed, the issue of homework has generated debates not only in schools but also in scientific circles and the media in every country including Canada for over a century (Cooper, 2001, Deslandes, 2009).

Quebec, as one of the provinces of Canada, is no exception. At this point, it is important to note that education is under provincial, not federal, jurisdiction (Deslandes \& Lemieux, 2005). Homework is usually defined as «tasks assigned to students by schoolteachers that are intended to be carried out during non-school hours » (Cooper, 2001, p. 3). Several perspectives have been used to approach and debate the issue of homework including among other things: (1) political and cultural contexts; (2) homework characteristics, that is, type, length, frequency; (3) parental involvement and responsibilities; (3) school practices and (4) importance and benefits of homework (Deslandes, 2009). Despite the great number of work conducted on the effectiveness of homework on students' performance, controversy still persists at least at the elementary level (Cooper, Robinson \& Patall, 2006). Endeavoring to provide some elements of response to this complexity, Hallam (2004) has provided a multidimensional homework model. According to the author, the following factors interact with each other when considering the outcomes of homework: (1) societal and cultural factors (e.g., political pressures, economic conditions); (2) students characteristics (e.g., self-esteem, attitudes, prior knowledge ); (3) school factors (e.g., resources, expectations, quality of teaching); (4) home factors (e.g., involvement and interest of parents, resources, physical environment); (5) nature of the task (e.g., type, amount, purpose, relevance of task); (6) presentation of the task (explanations, links to the curriculum, provision of materials), and (7) process of doing homework (tasks oriented strategies).

Yet, some questions remain without clear-cut answers or are recurrent every year at the start of the school year like "What is meant exactly by homework? Should teachers assign homework everynight? What are the benefits of homework? What is the parents' role in homework? » (Deslandes, 2009, p. 1). In reaction to this prevalent context of debate and controversy, the Québec Conseil supérieur de l'Éducation(CSE) produced in 2010 a brief on that topic to the Minister of Education, Recreation and Sport (Note 1). The objective was not to refute the relevance of homework because it has always been a near-universal practice in Québec elementary schools (CSE, 2010). The purpose was rather to provide guiding approaches in the area of homework and to translate them into practice. Its first recommendation was to consider homework at the local level and to analyze student needs 
and the characteristics of their families and environment. In other words, family needs and limits must be taken into consideration by teachers when assigning homework (Deslandes, Rousseau, Rousseau, Descôteaux \& Hardy, 2008).

In line with that recommendation, a governing board of a rural Quebec elementary school chose to include in its Success Plan as one of the measures to fulfill the goals of its Educational Project (Education Act (Note 2), c-1-13.3, Section 36) a collective reflection on homework (see also Deslandes \&Lemieux, 2005). The school principal sent an e-mail message to Dr. Deslandes on March 2, 2016, requesting ideas and help on ways to conduct the reflection. Exchanges via the telephonefollowed on March 22 and April 1 in view of preparing the formative intervention. First, the process objective and the criteria for selecting the participants were defined. Regarding the latter ones, it was decided to invite among the 22 teachers only those who were more experienced and less likely to be posted at another school and for whom it was possible to easily find a substitute teacher. The Change Laboratory (CL) methodology anchored in Cultural-Historical Activity Theory (CHAT) (Engeström, 1987, 2001,2015 ) and the role of the research-interventionist was also briefly explained to the school principal.

A CL refers to a mode of intervention and research led by two researchers and involving a small group of diverse participants willing to understand, develop and test new forms of actions (Engeström, 2011; Virkkunen \& Newnham, 2013). This method suggests that the intervention research team and stakeholders work together to identify and deal with problems and to create new tools to overcome a problem situation. Usually a CL has 5-12 meetings to analyze and clarify the challenges in the environment and possible joint solution models (Engeström, 2001; Virkkunen \& Newnham, 2013). The meetings are videotaped. Studies have shown that analysis of the exchanges between participants may help to identify the forms of participants' emerging transformative agency (Engeström, 2015). Typically, the Change Laboratory method comprises six phases : 1) questioning and criticising the actual practice; 2) analyzing the situation; 3) modeling the new solution; 4) examining and testing the model; 5) implementing the model and 6) reflecting and consolidating (see also Deslandes \& Barma, 2015). The present work corresponds to the first phase, that is the questioning one (Virkkunen \& Newnham, 2013).

\section{Theoretical Frameworks}

This study is grounded into the Change Laboratory (CL) intervention and research method(Engeström, 2001, 2007) that is based on CHAT (Engeström, 1987, 2015) and on Expansive Learning Theory.Drawing on the work of Vygotsky, Leont'ev and recently from Engeström and Sannino, third generation Activity Theory (Engestrom, 2001, 2007, 2010) it is possible to envision a transformation of teacher-parent collaboration within the context of homework (object) with greater educational success (learning and autonomy) as the outcome.

An activity system is always the minimal unit of analysis. It is oriented towards the object of study and mediated by artefacts or instruments. The system of activity corresponds to actions that are carried out by both individuals and a community. These actions depend on the conditions of implementation and imply a motivation shared by all the actors concerned in 
the pursuit of a common objective in such a way that a new form of activity takes shape and makes sense for all (Barma, 2008; Engeström, 1987). The purpose of the activity is constantly moving and cannot be reduced to short-term goals (Barma, 2008). The study of the activity pursued by the subjects is no longer centered solely on the psychology of an individual but also on the interactions between the individual and the various tools and the individual and the other actors which implies a necessary consideration of the roles and division of work of the members (Engeström, 2001).The teachers associated with a shared and targeted activity system act on a common goal (improved collaboration), and they experience recurrent tensions that result from rules established in their respective environments, which often require clarification of roles and influence the division of labor. Figure 1 shows the current analysis unit and its components and relationships. The subject or viewpoint from which the activity is analyzed (in this case, elementary teachers), the object is the transformation of teacher-parent collaboration within the context of homework with a view to more appropriate parental involvement in order to achieve greater educational success (learning and autonomy as expected results). Another pole of the model corresponds to the tools or artifacts used by the teachers, in this case (e.g., instrumental resources, homework strategies, communication modes) to achieve their goal. The lower part of the triangle puts into evidence the mediating role played by the socio-institutional dimension of human activity. The rules pole refers to expectations, school policies, norms, values, beliefs and ideologies that regulate actions and interactions within the system. The community component consists in this case of the other teachers, the principal and parents of the students attending the targeted school. At last, the division of labor dimension has to do with the changes in role, tasks and responsibilities among members of the community.

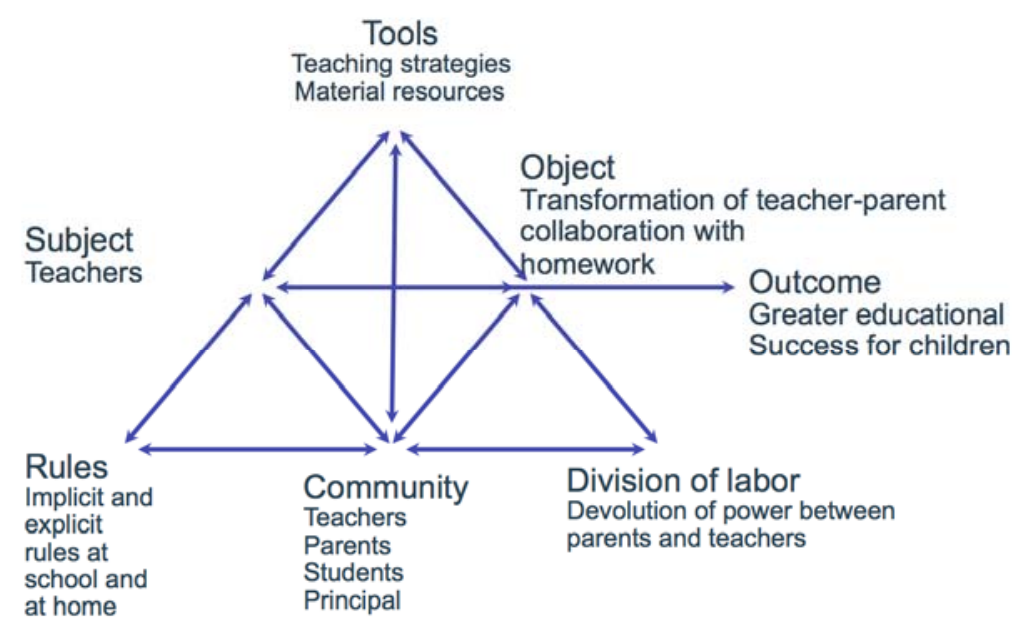

Figure 1. Activity Theory Model adapted from Engeström, 2010 to homework topic

Of uppermost relevancy in CHAT is the notion of transformative agency that allows to look for possible collective change actions (Haapasaari, Engeström \& Kerosuo, 2014). It is mainly through talk or dialogue that changes first emerge in a collective interaction over time.This systemic transformation or expansion from actions to new activity is grounded in the theory 
of expansive learning which refers to the process of ascending from the abstract to the concrete. Haapasaari et al. (2014) identified six forms of participants' emerging agency which they called expressions of transformative agency: (1) resisting the change; (2) criticising the current situation; change-oriented, (3) explicating new possibilities, relating to past positive experiences, (4) envisioning new patterns for the activity, (5) committing to concrete actions, and (6) reflecting on the process after a completed cycle (p. 11). This transformative agency varies along with the phases in CL sessions as they evolve over time. In this paper, we are interested in the occurrence and frequency of the first five types of transformative agency within a first CL session on the issue of homework. The sixth type cannot be included because the cycle is just at its beginning.

\section{Method}

\subsection{Double stimulation}

Vygotsky's principle of double stimulation is at the core of the methodology of the CL. In the current CL, our own homework research program results (Deslandes, 2009; Deslandes \& Barma, 2018) were the first stimulus. This type of "mirror data" is intended to trigger a reaction from the participants and to induce debates among the participants (Engeström \& Sannino, 2013). Itis fruitful to understand the way individuals make sense of a complex problem (Sannino, 2015). It makes it possible to go deeper into the aspect of the subject and better describe why and how participants commit to pursue an activity. To break away from a situation of conflict of motives, agency needs to emerge. "Thus, agency refers to the subject's willed quest for transformation. It transpires in a problematic, poly motivated situation in which the subject evaluates and interprets the circumstances, makes decisions according to the interpretations and acts upon these decisions" (Engeström \& Sannino, 2013, translated from French to English, pp. 3-4). The conflictual situation identified by the researchers and the participants constitutes the first stimulus and it is a necessary element to trigger transformative agency (Engeström \& Sannino, 2013, p. 4). In so doing, they also interiorize, create and use new mental functions to break away from a paralyzing situation (Engeström, 2007). For example, a teacher would employ an external artefact (conceptual tool like a pedagogical strategy) as a second stimulus, investing it with meaning in order to make a conscious decision and act on it.

If we revisit the pertinence of double stimulation insofar as the challenge faced when applying it in the schools, and more specifically, to the core of teachers' practice is concerned, we agree with McNicholl and Childs (2010) when they point out that, "picking up on Vygotsky's attention to externalisation alongside internalization in the process of learning, we would [...] argue that teachers in school are not only shaped by their surroundings but they shape them by their actions as they contribute to the knowledge that is locally distributed; and at the same time they learn a lot about teaching" (p. 57). In the steps of Vygotsky's (1927) proposal, by mastering socially constructed tools, teachers who engage in such an activity will create new meanings and model new social structures around them (Edwards, 2010).

As far as the core of the challenge of homework is concerned, the arguments we put forward in this paper are that Vygotsky's principle of double stimulation will: 1) allow us to better 
understand how teachers react, resolve, or reflect on a problematic situation they face in their practice; 2) help us illustrate how they engage in wilful actions to make parents join their discussions on the issue of homework. In this paper, we documented the expansive learning actions of 11 elementary school teachers after we presented them mirror data (first stimulus).

\subsection{Data Collection and analysis}

The group of participants included 11 teachers (2 Cycle One, 3 Cycle Two and 6, Cycle Three), working at the same elementary school site and three observers ( 1 school principal, 2 researchers, face-to-face and on Skype). Note that in this first session, the school principal asked to be an observer and not to intervene. All staff members signed a consent form. As said previously, at the start of the session, the research-interventionist who acted as a moderator presented some of our own homework research program findings (Deslandes, 2009; Deslandes \& Barma, 2018)as mirror data as a first stimulus, that is evidence-based data from prior studies, in order to foster a reflection on the issue of homework. The two main questions that guided the first CL session are: 1) Who are your students and their families? 2) What are your homework practices put into place in function of your teaching cycle? The videotaped session lasted for 120 minutes. The data were transcribedby a well-trained research assistant and the analysis was realized by the two researchers through the identification of units of meaning with a single idea per segment (in accordance to Haapasaari, et al. 2014). The focal point of this article lies on the participants' production of different types of expressions of transformative agency during the questioning phase of CL processes. It also aims at identifying the topics of discussion linked to the different types of transformative agency.

\section{Findings}

A total of 283 expressions of agency were found in the exchanges of the first CL session (see Table 1). Explicating, that is reference to past positive experiences and highlighting of potential new possibilities and exciting challenges is the most frequent type $(n=119)$ followed by criticising in line with identification of problems met in the past or directed at the current activity ( $\mathrm{n}=110)$. The least frequent type of expressions of agency was committing to actions $(\mathrm{n}=1)$, which is quite normal given the early stage of the process of transformative agency. About an equal number of transformative expressions were related to imagining / envisioning new ways of doing things $(n=29)$ and resistance $(n=24)$ to changes. Table 1 and Figure 2 show the number of expressions of agency for each participant. Table 2presents some excerpts that illustrate the types of transformative expressions. Furthermore, we were also interested in identifying the CHAT poles or components at which the types of emerging agency were directed. 
Table 1. Number of expressions of agency for each participant

\begin{tabular}{|c|c|c|c|c|c|c|c|}
\hline & Resisting & Criticising & Explicating & Envisioning & $\begin{array}{l}\text { Committing to } \\
\text { actions }\end{array}$ & $\begin{array}{l}\text { Taking } \\
\text { actions }\end{array}$ & Total \\
\hline Teacher 1 & 3 & 10 & 12 & 4 & 0 & 0 & 29 \\
\hline Teacher 2 & 1 & 0 & 4 & 0 & 0 & 0 & 5 \\
\hline Teacher 3 & 1 & 4 & 9 & 3 & 0 & 0 & 17 \\
\hline Teacher 4 & 6 & 18 & 10 & 7 & 1 & 0 & 42 \\
\hline Teacher 5 & 1 & 13 & 14 & 1 & 0 & 0 & 29 \\
\hline Teacher 6 & 0 & 7 & 2 & 3 & 0 & 0 & 12 \\
\hline Teacher 7 & 0 & 4 & 9 & 0 & 0 & 0 & 13 \\
\hline Teacher 8 & 0 & 10 & 15 & 5 & 0 & 0 & 30 \\
\hline Teacher 9 & 2 & 4 & 8 & 1 & 0 & 0 & 15 \\
\hline Teacher 10 & 7 & 19 & 20 & 3 & 0 & 0 & 49 \\
\hline Teacher 11 & 3 & 21 & 16 & 2 & 0 & 0 & 42 \\
\hline Total & 24 & 110 & 119 & 29 & 1 & 0 & 283 \\
\hline
\end{tabular}

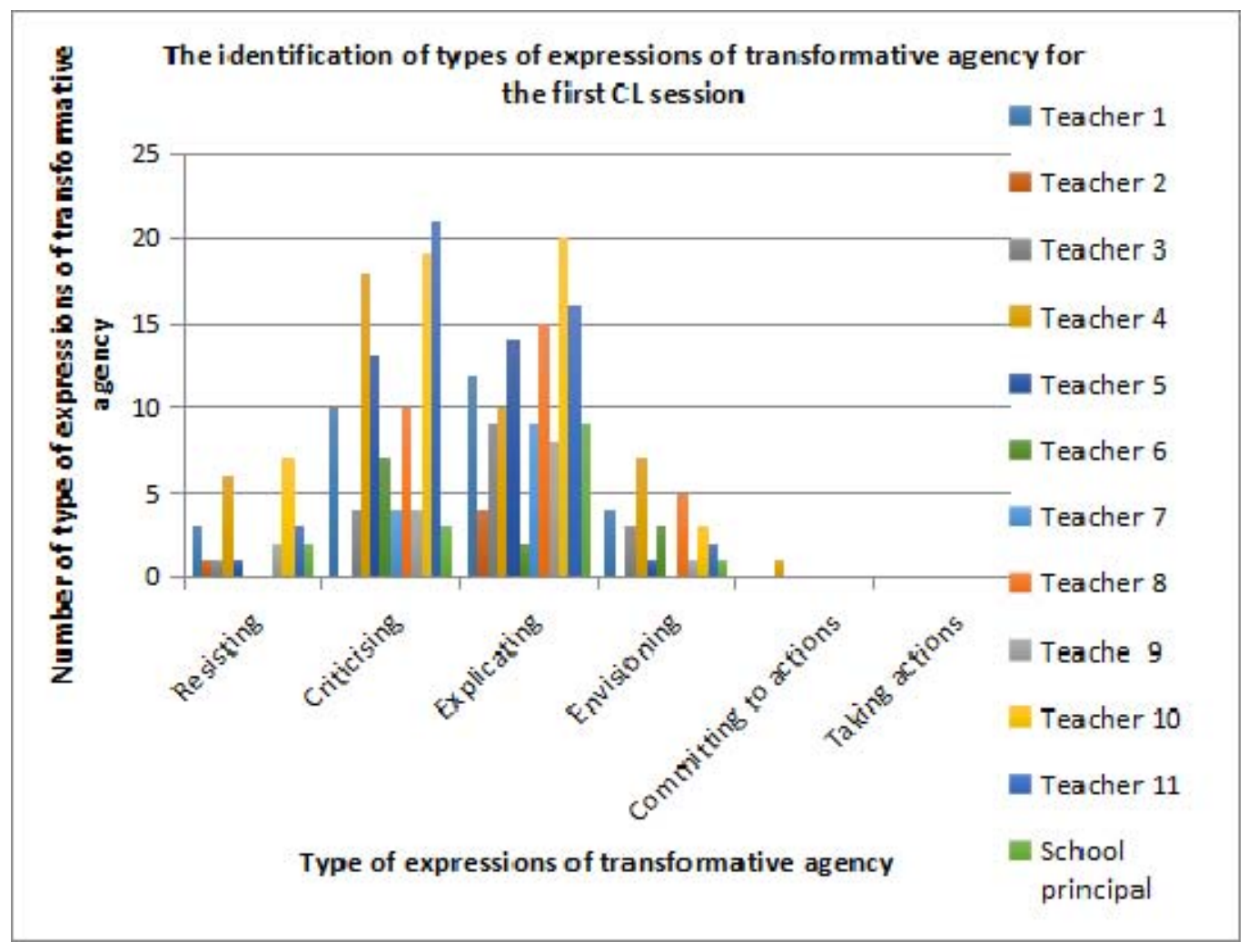

Figure 2. Identification of the types of expressions of transformative agency 
Table 2. Frequency of types of expressions of transformative agency in the First CL session

\begin{tabular}{|l|l|l|}
\hline $\begin{array}{l}\text { Types of } \\
\text { expressions }\end{array}$ & Number & \multicolumn{1}{c|}{ Examples } \\
\hline \multicolumn{1}{|c|}{ Explicating } & 119 & $\begin{array}{l}\text { There are some parents here who are teachers and } \\
\text { also parents. Here, it is more than a school, it is a } \\
\text { living environment(S-11). }\end{array}$ \\
\hline Criticising & 110 & $\begin{array}{l}\text { It is certain that with their children going to school } \\
\text { now, the homework practices have completely } \\
\text { changed(A-13). }\end{array}$ \\
\hline Envisioning & 29 & $\begin{array}{l}\text { We have been working together for a long time and } \\
\text { we have changed and changed and we are constantly } \\
\text { asking ourselves questions(K-21). }\end{array}$ \\
\hline Resistance & 24 & $\begin{array}{l}\text { Since January, it's over. Because my child is in the } \\
\text { first grade, so I suffer homework(C-14). }\end{array}$ \\
\hline $\begin{array}{l}\text { Committing } \\
\text { toactions }\end{array}$ & 1 & $\begin{array}{l}\text { I keep the students during a school «remediation» } \\
\text { period because homework must be completed, it is } \\
\text { not a choice, it is an obligation (H-21). }\end{array}$ \\
\hline
\end{tabular}

\subsection{Explicating}

Expressions of explicating possibilities by the participants (subject) were highest when they were directed at their expectations regarding parents involvement in homework practices. They were mostly oriented towards the rules and division of labor poles. Each grade level teacher described her practices and strategies with respect to homework assignments. For instance, in the first grade, one teacher assigns four books a week and as a rule (rule pole), asks parents to read for 15 minutes at the most, at a time. Another one sends home a variety of storybooks and expects parents to manage the turnover of the books (rules pole). In the same line of thought, a grade two teacher says: There is a mathematical homework that is more than just practice; our vision [...] is to allow parents to have some kind of follow-up on what the child is doing in class(rules pole)(I-16). In grade 3, teachers recommend to parents to have children read different types of texts including recipes, novels or comic books over a period of 11 days, from day 6 through day 6 (F-17) (division of labor pole). In grade 4, teachers suggest some activities to choose from and assign some verb conjugation at different tenses, and two trace sheets. The parents are asked to make sure traces of the work are written on the sheets (division of labor pole).

In the fifth grade, the teachers plan the work from day 3 through day $3:[\ldots]$ There is $a$ routine that has been established [...]I am a very methodical person(K-22) (rule pole). Students are given four assignments on a 6-day cycle that can sometimes overlap on 11 days. The assignments include mathematics and verb conjugation and they must keep traces of their work. Teachers offer two to three class period workshops during which students can 
practice the notions seen in class, exchange ideas and strategies and work in teams. The workshops are not assignments but if they are not completed, they become homework assignments. The teachers aim to develop the students' autonomy and sense of responsibility. Students are given the choice : either they complete the assignment at home or they do it during school lunch time (J-24). (toolspole).

In the sixth grade, one teacher does things a little differently. Students do have math and vocabulary assignments and some practice that are not considered as homework. They are given a deadline with the possibility of handing in their homework sooner and have it corrected. At the beginning of the year, she informs the parents: There is no assignment that your child is not able to do alone. Make him/her use the Bescherelle grammar... He/she must practice(D-27). She also says : I put a lot of emphasis on reading, I talk a lot about it at the first meeting with a group of parents; I require 20 minutes of reading per night, about anything (D-27). Teachers also explicate the different possibilities of parents' getting in touch with them: We are very open to meet them and to talk to them on the phone, by e-mail too(B-27) (toolspole).

\subsection{Criticising}

During the first minutes of the session, the participants criticised and highlighted the challenges related to homework with respect to the community (parents) and directed at the rules pole. The parents' low SES status, the mothers' low level of schooling, some parents' past negative experience as learning difficulty students having attended the same school and parents of children with learning difficulties elicit a great number of criticisms regarding parents' expected level of involvement (rules pole). The following excerpts illustrate some themes of criticising related to the community and directed at the rules pole:

I am thinking of a single mother, in a disadvantaged environment. (H-21). The mother who had learning difficulties, who did not do well in school, just can't feel at ease doing homework (A-48). We have parents of children who have not had a positive school experience, so they are not behind their child [...](B-9); For some parents, it's a real puzzle and with learning difficulty students, homework can easily take $1 \mathrm{~h}-1 \mathrm{~h} 30 \mathrm{per}$ night to complete(F-17). We can see the parents who are more available or who are in more advantaged environments. For the others it is more difficult (F-17). [...]The child who has no parent who can sit next to him/her(G-20).

Some teachers also criticised the challenges that parents must face with respect to classroom organization and homework assignments deadlines that vary between the cycles (toolspole)and require much adaptation and adjustment on the parents' part (division of labor pole). Here are some examples of criticising expressions:

The transition of no longer having homework but only lessons and leaving traces [...]but our survey results told us that parents needed a canvas. They found it hard to be left without any type of structure (G-19). At the beginning of the year, the parents find it difficult to think in terms of "from day 2 to day 2 ", it is no longer from Monday to Friday(G-22). As parent, it means that it's not the same cycle. I'm going to get mixed-up with another of my children 
having a different cycle period(A-23). We work differently, that is, we assign homework on Friday, we have no cycle period. I do not like working with «day 1 to day $1 »(\mathrm{~B}-30)$.

Other criticisings are also related to the division of labor pole, as shown in the following excerpts :

We know that for some parents, the routine of the evening is not easy, often the child arrives early at the school childcare center and leaves late at the end of the afternoon plus other activities like gym, skating...So, we offer the students the opportunity to do homework in class with us(C-26).Others deplore: parents must understand that it is not their homework but their child's homework. Parents sometimes do homework themselves (B-40).

Teachers reckon that parents whose child enters grade 3 or whose child has learning difficulties meet more challenges and need more help in accompanying as shown in the following statements: [...]The gap between the second and the third grades is quite high(E-17). Those with dyslexia find that homework time can be excessively long even more so with an added attention deficit disorder (D-29). Above all, the fact that some of them hold a double role, as a teacher and as a parent, helps them to highlight the challenges linked to their responsibilities with homework helping, even more importantly when the child ishaving difficulties: I think that our vision when we are a parent of a child having learning difficulties changes (H-29).

The toolspole also invoked expressions of criticising. As one participant said, parents needed more structured tools in order to help their child with homework: [...]For some parents I had to prepare a paper on how to plan and organize the homework period at home (F-17). [...] they needed a canvas (G-19). [...] children need some work structure; often parents do not have any (H-35). Others report complaints from some students' fathers regarding the lack of clarity in the homework guidelines : [...] When my youngest child was in the first grade, I showed his homework to my husband and he said : "it's not clear what you want". Last year, my colleague's husband also said: “what do you mean?"(A-46). They also expressed criticism with respect to some communication modes with parents (toolspole): Sometimes, parents arrive at school without any notice; we're stuck, we have our students in the classroom [...], we prefer that the parents make an appointment (B-25).

Some criticisings were directed at the activity itself and referred to previous ways of doing things. One teacher declared: It is the first time that I'm hearing about what the teachers are doing in the other grade levels (F-39). Some participants became aware of the high variety in the terminology to refer to homework and that are different from one cycle to another: Perhaps, it is about the language that is being used. For instance, some talk about keeping study traces; I call it homework [...](D-40). Another one questions the idea of having only one meeting with the group of parents at the beginning of the year: Perhaps, what emerges is that it is not enough one meeting with the parents at the start of the school year (D-44). One teacher adds: A lot is said to the parents between 19:00 and 20:00 o'clock. They come to visit the classroom and they are given information documents (H-44). 


\subsection{Imagining / Envisioning}

The imagining and envisioning-oriented expressions emerged much less frequently than the explicating and criticising tones. They were mostly related to the toolspole. They referred to suggestions of new ways of working: My colleague thought about it all summer. She reflected on what we want, what our goal is, how we can make it easier (H-21) (toolspole). Some teachers thought of a new work structure to better help students and at the same time, to allow them to gradually develop their autonomy (K-27). They imagined doing reading assignments in different settings :.......]We require 15 minutes of reading per night; we tell them that it can be done while taking their bath, in the washroom, adding some humor to make them more interested to read (K-26). One teacher tries to think of ways of reinforcing students who complete their homework over a period of time by inviting them to have a pizza lunch with her (B-34). Another one dreams of having the power to convince students that they can enjoy homework: Homework or studying lessons can be fun. I wish I had the power to convince them that doing homework or studying lessons can be fun (H-35)(toolspole).Some prefer to offer some workshops : [...]The workshops are homework that we no longer send home; they are workshops but if they are not finished, they become homework (G-20). [...] we give them work to be done in the classroom [...] (G-20). One teacher continues: There are two periods per cycle during which they can do homework. They also have the school library period to do homework (K-23).A teacher says it is better in her case to use her cellular phone while in school to call back some parents and have the students' file in front of her (I-37) (toolspole). Two participants think of the possibility of using common homework-related words across the same grade levels (F-39, D-41) (toolspole). Others suggest to have a third meeting with a group of parents in order to better equip them in helping their child (D-45) and thus facilitate their work(H-49) (division of labor pole). One participant envisions having a CL session that includes some parents : While talking to you, I realize that we should not assume we know what parents think; we could possibly have a group of parents in a next session (H-48).

\subsection{Resistance}

The transformative expressions containing resistance were related either to the parents(rules pole), to themselves in their double role, parent and teacher (subjectpole), to homework as the object and to the current activity. For example, regarding parents' expected involvement, teachers reveal that some of them are already paying for tutors' help and that certain parents are very emotional about their involvement in homework (division of labor pole). Another points out : After 20 minutes doing homework, I usually have way less patience [...] I tell my parents to let it go [...]I am a parent-teacher(SC-29). One teacher indicates that she herself resists to some types of homework: This year I even went so far as to remove as homework the word-labels. My colleagues did not do that(A-13). One participant shows a reluctance to any change in the use of homework terminology (rules pole) : I wonder, do we have to standardize the homework terminology across the grades ?(G-38). Another believes that it is quite normal to have different ways of doing things : A parent might say that last year, it was simpler, and this year, it is more complicated; it is fine because in daily life, in the real world, we meet all sorts of situations (B-40) (rules pole). Regarding the current activity, a teacher 
says : I did not feel the need to participate in the session because I thought what I was doing was okay(AB-44). In line with resisting the pursuit of any change, a participant reflects : Am I interested into coming back? If I come to discuss to discuss, what will it bring to me? What about if it brings to me nothing (B-49).

\subsection{Committing to actions}

As expected, the few commitments to taking concrete actions were expressed toward the end of the CL session. Two participants had already engaged in some types of changes offering for instance, some remediation periods to complete homework. They strongly believe that students need to work in a structured environment. (G-21, H-35) (rules pole)Interestingly, some committing to actions were related to the tools. One admits to be receptive to technology and to accept parents' texto messages (toolspole). It's found to be both practical and rapid. Another invites parents to get in touch with her through the school e-mail address (A-37).

\section{Discussion and conclusion}

The aim of this article was to prepare, implement and analyze the findings of a first session in the context of a CL intervention. A first CL session is oriented toward questioning the participants so they engage, with the researchers, in a discussion that will highlight their needs and lead to a common understanding of their shared activity. Methodologically, it requests an important ethnographic input and work done by the research team to build a proper and meaningful first stimulus that gives an overwiew of the issue of homework at an elementary school. It requests a cultural and historical documentation of the evolution of the problem over a certain period of time: this is in coherence with the CHAT framework. As presented in the theoretical framework, we examined the types of expressions of transformative agency found in the spoken discourse and tried to visualize in what ways they could eventually lead to the transformation of the current homework practices and the teacher-parent collaboration within the context of homework (object). Our findings support Engeström's (2011) classification of the types of expressions of transformative agency. As found in Haapasaari et al. (2014)'s study, the most frequent expressions expressed during the CL session were explicating (42\%) and criticizing (39\%). The types and purposes of homework, the deadline for handing in the assignments and the classroom organization (rulespole) and the teachers' expectations regarding parents' involvement (division of laborpole) and students' autonomy development were the most discussed topics under the explicating expressions. On their part, criticism expressions highlighted the challenges met by parents (community pole) regarding their involvement in homework (division of laborpole) and linked to their low SES and their low level of schooling. Criticism expressions also put into light other parents' challenges linked to the classroom organization and homework deadlines as well as the sharing of responsibilities regarding homework (division of labor pole). Through criticisms, teachers (subjects) realized that their double role as teacher and as parents made it easier to understand the parents' challenges regarding homework especially when the child is having learning difficulties. These criticisms lead the participants to imagine more uniformity in the homework terminology (toolspole) across the grades, to 
imagine offering a workshop to parents (community pole) on how to effectively accompany their child in homework and to envision having parents joint teachers as participants in another CL as a follow-up session so as to give them the opportunity to express their own needs. Regarding the resistance expressions, they were the least frequent and they emerged mainly from one participant who seemed to have doubts concerning the utility for her to participate in another CL session.

Figure 3 depicts what teachers would have to put into place so that parents get involved in more appropriate ways with homework. The analysis of transformative agentive expressions reveals some recurrent tensions (discursive manifestations of contradictions) related to the roles and division of labor (broken arrows in the figure).

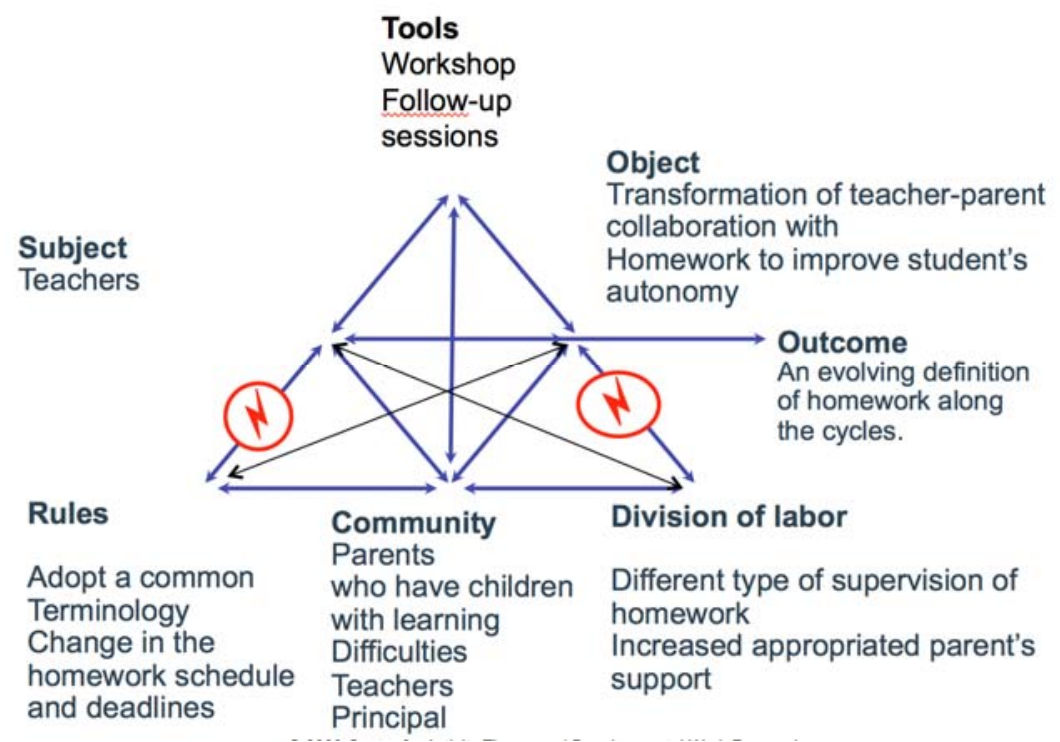

Figure 3. Teachers' agenda to better fit parents' involvement with homework

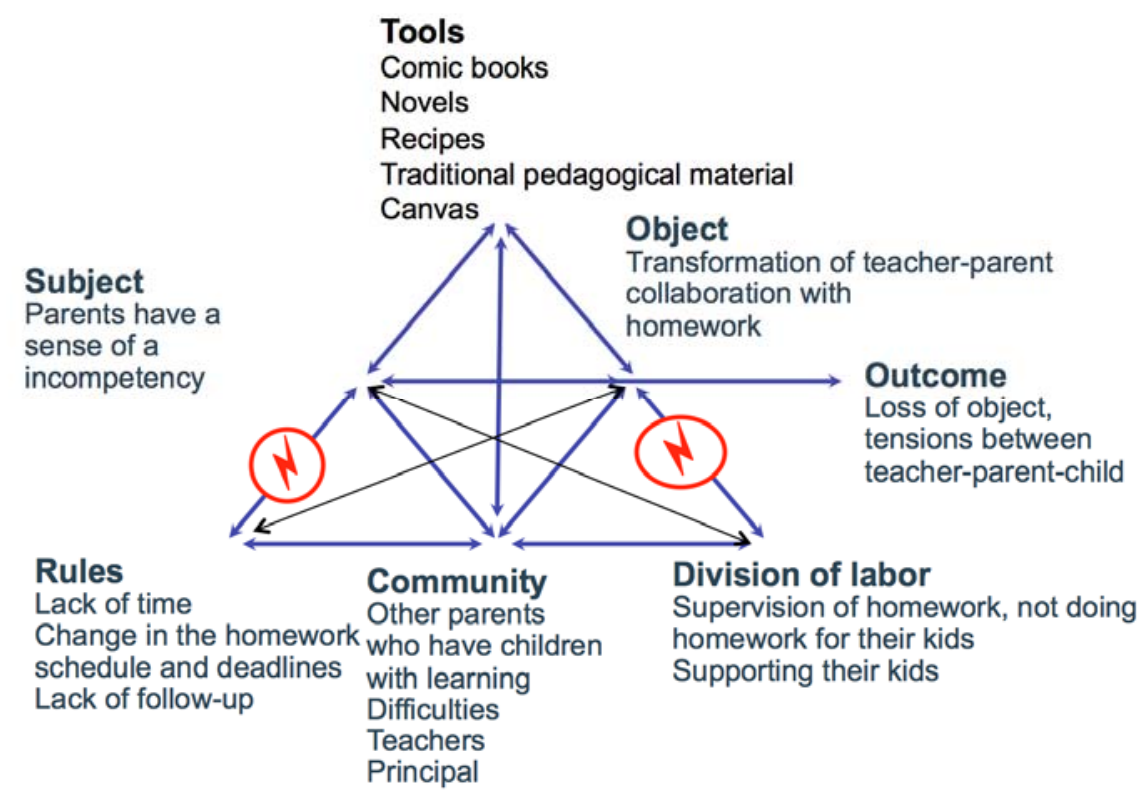

Figure 4. Teachers' perceptions and expectations of parents' involvement with homework 
According to the teachers, some parents seemed to experience a lack of competency and a lack of time when it comes to supervising their child's homework. Some are tempted to get over involved, that is, do the homework themselves. At the time of the recorded session, our analysis of the transformative expressions seemed to indicate a loss in the object of the activity system ie the purpose of giving homework because parents did not seem to share the same vision. Figure 4illustrates an activity system emerging from the analysis of the teachers' discourse as they explicate and criticize parent's involvement with homework. The figure also shows some recurrent tensions that we previously exemplified at the poles rules and division of labor.

Despite the fact that only the first phase of a CL is being presented, we strongly believe in this intervention and research method as being appropriate to support a collective consideration of homework at the local level. Already, we can give a glance at different solutions that could be prioritized and then modeled by the stakeholders in the next CL sessions. They could range from creating a parents networking to provide a space for more exchanges between teachers of a same level in order to establish a certain homogeneity in word usage and to plan the transition in homework policies and practices from one grade to another. Furthermore, teachers who are also parents could be excellent resource persons to remind colleagues to provide clearer and simplified directives regarding homework. All in all, the $\mathrm{CL}$ is an example of a process that can be used when looking for not only radical changes but also practical and pragmatic improvements concerning a given issue.

\section{References}

Barma, S. (2008). Un contexte de renouvellement de pratiques en éducation aux sciences et aux technologies: Une étude de cas réalisée sous l'angle de la théorie de l'activité (Doctoral dissertation, Université Laval).

Deslandes, R. (2009). Introduction. In R. Deslandes (Ed.), International perspectives on student outcomes and homework: Family-school-community partnerships (pp. 1-6). New York, NY: Routledge

Deslandes, R. \& Barma, S. (2015). Les relations entre les enseignants et les parents: premières étapes d'intervention d'un Laboratoire du changement [Relationships between teachers and parents: First intervention steps of a Change Laboratory]Revue internationale du CRIRES: Innover dans la tradition de Vygotsky, 3(1), 20-34.

Deslandes, R., \& Barma, S. (2016). Revisiting the challenges linked to parenting and home-school relationships at the high school level. Canadian Journal of Education, 39(4), $1-32$

Deslandes, R., \& Barma, S. (2018). The challenge of improving homework processes and benefits: Insights from two intervention research sessions with teachers and parents of an elementary school. International Journal about Parents in Education, 10(1), 47-58. 
Deslandes, R., \& Lemieux, A. (2005). The place of family and community within schools in Québec. In D.B. Hiatt-Michael (Ed.), Promising Practices in Family Involvement in Schooling Across the Continents (pp.93-112), Connecticut: Information Age Publishing.

Deslandes, R. Rousseau, N., Rousseau, M., Descôteaux, G., \& Hardy, V. (2008). Regard parental sur les devoirs et leçons en fonction des caractéristiques familiales et du rendement de l'école. Revue canadienne de l'Éducation, 31(4), 836-860.

Conseil supérieur de l'éducation (2010). Toward a consideration of homework in elementary schools. Abridged version. Quebec. https:/www.cse.gouv.qc.ca/fichiers/documents/publications/Avis/50-0467-01a.pdf

Cooper, H. (2001, $2^{\text {nd }}$ ed.). The battle over homework. Common ground for administrators, teachers, and parents. Thousand Oaks, CA : Corwin Press.

Cooper, H., Robinson, J. C., \& Patall, E. A. (2006). Does homework improve academic achievement? A synthesis of research, 1987-2003. Review of Educational Research, 76(1), 1-62. https://doi.org/10.3102/00346543076001001

Edwards, A. (2010). Being an expert professional practitioner: The relational turn in expertise (Vol. 3). Springer science \& business media. https://doi.org/10.1007/978-90-481-3969-9

Engeström, Y. (1987). Learning by expanding: An activity-theoretical approach to developmental research, [online] Retrieved from http://lchc.ucsd.edu/mca/Paper/Engestrom/expanding/toc.htm

Engeström, Y. (2001). Expansive learning at work: toward an activity-theoretical reconceptualization. Journal of Education and Work, 14(1), 133-156. https://doi.org/10.1080/13639080020028747

Engeström, Y. (2007). Enriching the theory of expansive learning: Lessons from journeys toward coconfiguration. Mind, culture, and activity, 14(1-2), 23-39. https://doi.org/10.1080/10749030701307689

Engeström, Y. (2010). From design experiments to formative interventions. University of Helsinki, Center for Activity Theory and Developmental Work Research. https://doi.org/10.1177/0959354311419252

Engeström, Y. (2011). From design experiments to formative interventions. Theory \& Psychology, 21(4), 598-628. https://doi.org/10.1177/0959354311419252

Engeström, Y. (2015). Learning by expanding ( $2^{\text {nd }}$ edition): An activity-theoretical approach to developmental research. Cambridge University Press.

Engeström, Y., \& Sannino, A. (2010). Studies of expansive learning: Foundations, findings and future challenges. Educational research review, 5(1), 1-24. https://doi.org/10.1016/j.edurev.2009.12.002 


\section{Macrothink

Engeström, Y., \& Sannino, A. (2013). La volition et l'agentivité transformatrice: perspective théorique de l'activité. Revue internationale du CRIRES: innover dans la tradition de Vygotsky, 1(1), 4-19.

Haapasaari, A., Engeström, Y., \& Kerosuo, H. (2014). The emergence of learners' transformative agency in a Change Laboratory intervention. Journal of Education and Work. https://doi.org/10.1080/13639080.2014.900168

Hallam, S. (2004). Homework: Its uses and abuses https://content.ncetm.org.uk/itt/sec/KeelePGCEMaths2006/Research/Homework\%20Researc $\mathrm{h} /$ ReportSusanHallam.pdf

McNicholl, J., \& Childs, A. (2010). Taking a sociocultural perspective on science teachers' knowledge. In V. Ellis, A., \& P. Smagorinsky (Eds.), Cultural-historical perspectives on teacher education and development, 45-63.

Sannino, A. (2015). The principle of double stimulation: A path to volitional action. Learning, Culture and Social Interaction, 6, 1-15. https://doi.org/10.1016/j.lcsi.2015.01.001

Virkkunen, J., \& Newnham, D. (2013). The Change Laboratory: A tool for collaborative development of work activities.Sense Publishers. https://doi.org/10.1007/978-94-6209-326-3

Vygotsky, L. S. (1987). Problems of general psychology.

\section{Notes}

Note 1. Created in 1964 and comprising 22 representatives of the education community, the Conseil supérieur de l'éducation is an advisory body to the Minister of Education, Recreation and Sport.

Note 2. In 2002, amendments made to the Education Act by Bill 124 mandated the governing board to develop an educational project that includes the school's specific aims and the objectives intended to increase student success. The success plan (Art. 37.1) includes the measures to fulfill the objectives of the educational project, the procedures for the supervision and the methods for evaluating. 